\title{
Sustainability issues of by-product and waste management systems, to produce building material commodities: A comprehensive review of findings from a virtual special issue
}

DOI:

10.1016/j.resconrec.2019.04.001

Document Version

Final published version

Link to publication record in Manchester Research Explorer

Citation for published version (APA):

Ingrao, C., Arcidiacono, C., Bezama, A., loppolo, G., Winans, K. S., Koutinas , A., \& Gallego Schmid, A. (2019). Sustainability issues of by-product and waste management systems, to produce building material commodities: A comprehensive review of findings from a virtual special issue. Resources, Conservation and Recycling, 146, 358365. https://doi.org/10.1016/j.resconrec.2019.04.001

\section{Published in:}

Resources, Conservation and Recycling

\section{Citing this paper}

Please note that where the full-text provided on Manchester Research Explorer is the Author Accepted Manuscript or Proof version this may differ from the final Published version. If citing, it is advised that you check and use the publisher's definitive version.

\section{General rights}

Copyright and moral rights for the publications made accessible in the Research Explorer are retained by the authors and/or other copyright owners and it is a condition of accessing publications that users recognise and abide by the legal requirements associated with these rights.

\section{Takedown policy}

If you believe that this document breaches copyright please refer to the University of Manchester's Takedown Procedures [http://man.ac.uk/04Y6Bo] or contact uml.scholarlycommunications@manchester.ac.uk providing relevant details, so we can investigate your claim.

\section{OPEN ACCESS}


Editorial

\author{
Sustainability issues of by-product and waste management systems, to produce building material \\ commodities: A comprehensive review of findings from a virtual special issue
}

\section{Introduction}

The energy consumption associated with the life cycle of buildings accounts for around $40 \%$ of the global demand, thereby making buildings one of the most energy demanding sectors (Berardi, 2017; Kanchanapiya et al., 2018; Ingrao et al., 2018a). Two types of energy should be considered when investigating life cycle of buildings, namely the embodied energy and the operational one. The embodied energy is sequestered in buildings and building materials during all processes of production, on-site construction, and final demolition and disposal, and is characterised by the direct and the indirect component. The former is used for construction, maintenance, renovation and demolition of buildings, whilst the latter is consumed to produce all materials and auxiliaries that are utilised for building construction (Dixit et al., 2012). By contrast, the operational energy is spent to maintain the inside environment at the desired levels of comfort through a complex of activities, such as heating and cooling, lighting and operating building appliances (Ramesh et al., 2010; Kanchanapiya et al., 2018). The literature indicates that the operational energy is the largest contributor to the energy consumed in the life cycle of a building, because its share can vary between $70 \%$ and $90 \%$. Whilst, the embodied energy contribution generally ranges between $10 \%$ and $30 \%$, depending upon the building system considered (Asdrubali et al., 2013; Kanchanapiya et al., 2018; Ingrao et al., 2018a).

Therefore, to face today's climate change impact and other environmental challenges, the building sector should accommodate solutions that are environmentally sustainable and, at the same time, enable reduction of life cycle amounts of resources, materials, fuels and energy as consumed in buildings (La Rosa et al., 2014; Ingrao et al., 2018a). For this purpose, it is recommended that materials and technologies are selected and assessed from the early stages of design, to reduce the environmental burdens concerning not only to building construction, but also to the next phases of use (operation and maintenance) and end-of-life (Ingrao et al., 2016, 2018a). In particular, material selection is an essential element to be accounted for in the design of a building to reduce: consumption volumes of both embodied and operational energy; and life cycle environmental impact (Ingrao et al., 2017).

In this context, the usage of material commodities produced from by-products and/or wastes has been documented to be a valid solution in this sense. Both BREEAM and LEED, the two leading sustainability accreditation schemes, provide requirements to consider and minimise life cycle environmental burdens of building material commodities, and encourage utilising materials with high levels of recycled material content (Joyce et al., 2018).
The literature is increasingly rich of studies investigating such a research field. By way of example, Intini and Kühtz (2011) and Ingrao et al. (2014) assessed, from an environmental perspective, the production of polyester fibre mats for building thermal insulation obtained from postconsumer bottles made of Polyethylene Terephthalate (PET). From either of the two studies, it was found that the utilisation of such a waste material enables environmental gains that highly compensate the impacts coming from the most harmful processes involved. This makes such insulating mats environmentally competitive compared to those, also of natural origin, that are currently available in the market with equal function (Ingrao et al., 2014). Environmental benefits in the field of recycled materials for application in buildings were also highlighted by Rincon et al. (2014) specifically for rubber obtained from recycling of out-use tires. As a matter of fact, the authors performed Life Cycle Assessment (LCA) and emphasised upon the potential of using this material to form drainage layer for extensive green roofs and compared results with conventional roof systems (Ingrao et al., 2017).

Several other studies have been developed in recent years to assess, from a technical, environmental, and socio-economic perspective, utilisation of waste streams in the manufacturing of building construction materials and products, as one valid way to save natural resources and promote environmental sustainability (Kanchanapiya et al., 2018). This can be considered as a consequence of traditional resource management strategies straggling to stem the rising tide of resource consumption and attendant environmental challenges, particularly given historic paradigms that economic growth is fundamentally linked to a linear industrial economy (Babbitt et al., 2018). This type of economy has dominated the last 150 years and was based upon a one-way track model, according to which resources were extracted from the natural environment, converted into products providing economic value, with no plans made for reusing the generated wastes or actively regenerating the economy (Venkata Mohan et al., 2016; Babbitt et al., 2018; Ingrao et al., 2018b). Such an economy system appears as surprisingly wasteful in its model of value creation: as a matter of fact, current material recycling and waste-based energy recovery captures, in Europe, only an average of 5\% of the original raw material value (Ingrao et al., 2018b). So, it emerges that linear economies are totally unsustainable, both environmentally, and socio-economically (Korhonen et al., 2018; Ingrao et al., 2018b). Hence, the rationale for transitioning to circular models of the economy is evidently urgent, apart from being welldocumented in the scientific literature currently available in the sector. In addition to this, the size of the economic opportunity, as well as the wide range of benefits, is gradually emerging both from an analytical perspective and through the compelling case studies provided by early adopters and researchers worldwide (Ingrao et al., 2018b). Only now 


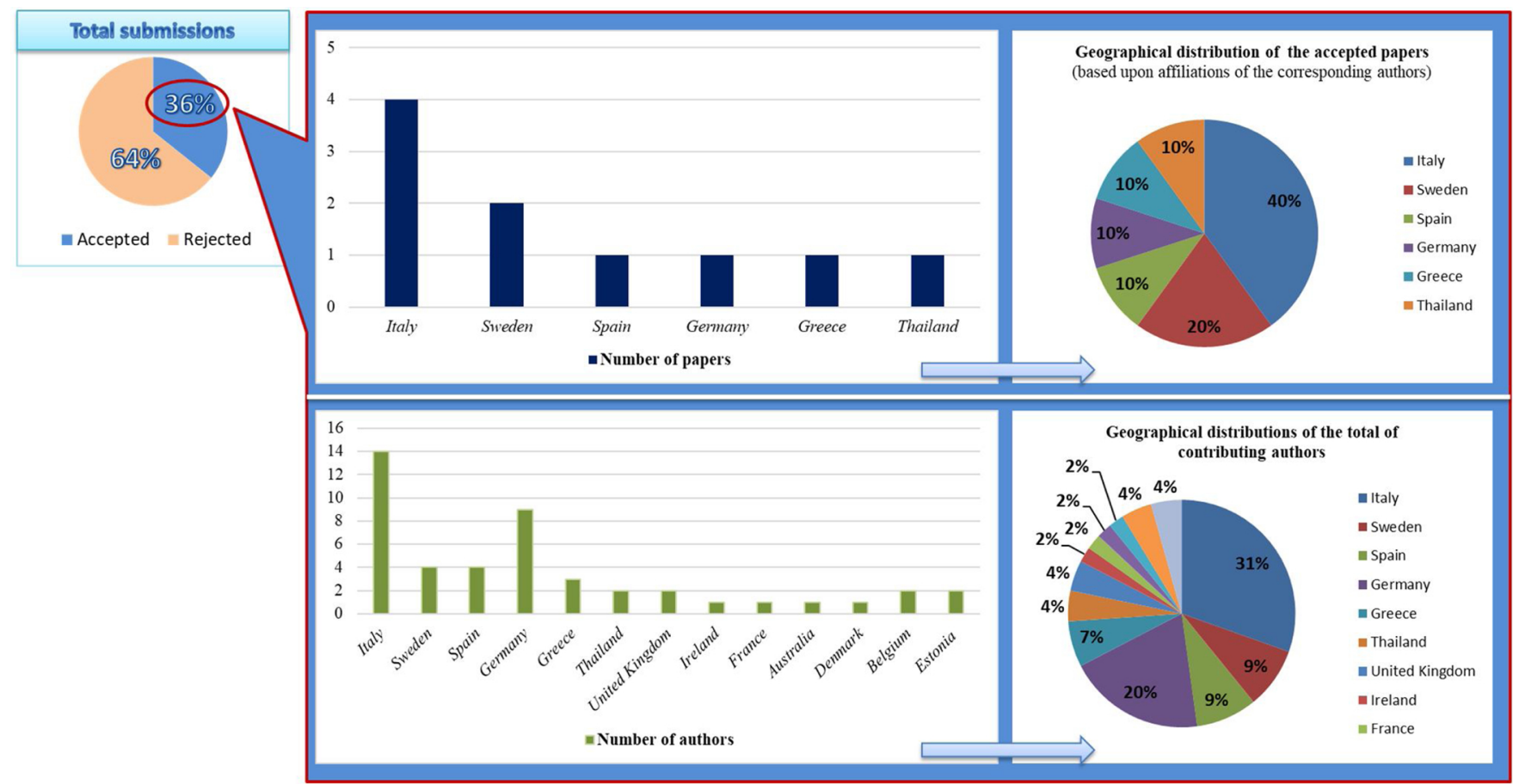

Fig. 1. This figure shows: the percentages of accepted and rejected papers with respect to the total submissions received; the geographical distribution of the papers (10) included in this VSI, based upon affiliations of the corresponding authors; and the geographical distribution of all authors (46) contributing to the papers accepted.

concrete efforts seem to have been devoted to shifting the policy framework from eco-destructive and resource-exhausting societies to resource conserving and environmentally friendly ones (Venkata Mohan et al., 2016; Ingrao et al., 2018b). The literature has documented that economy and environmental sustainability are strongly interconnected and contribute to their mutual development and improvement (Arbolino et al., 2017; Ingrao et al., 2018b).

In this context, Circular Economy (CE) is increasingly attracting interest and attention from both scholars and practitioners at the international level (Kirchherr et al., 2017). It is a highly-debated topic in the strategic management field, as it gives several opportunities for academia, decision- and policy-makers, and business (Ünal et al., 2019). CE is based upon implementation and promotion of circular flows to reduce environmental impacts, whilst maximising resource efficiency (Moreau et al., 2017; Saavendra et al., 2018; Ingrao et al., 2018b). In practice, CE offers a provocative alternative by: decoupling economic development from resource consumption; selecting non-extractive technologies and renewable materials, and returning valuable resources into productive usages. Maximising reuse and recycling of waste materials is one of the important paradigms which CE is centred upon (Arrigoni et al., 2018). As the consequence of this, there would be reduced net material consumption and, in theory, reduced environmental impact associated, overall, to the manufacturing system (Babbitt et al., 2018). Therefore, CE can play multiple key roles for sustainable development and its environmental, economic and social dimension (Korhonen et al., 2018).

$\mathrm{CE}$ is based upon affordable, effective and truly sustainable waste management systems, so as to positively contribute to sustainable development (Goulart Coelho and Lange, 2016). In turn, this enables reduction of cannibalisation of material and energy resources, resulting from the increasing globalisation and industrialisation phenomenon (Govindan, 2015). To this end, in a CE perspective, waste management systems should be focussed not only upon traditional disposal scenarios like landfilling but, also, upon integrated strategies for: development and optimisation of separate-municipal collection systems; and more environmentally sustainable recovery scenarios. With regard to this issue, landfill can be an expensive option if the cost of resource depletion and environmental pollution are considered, whilst recycling not only increases the efficiency of resources but, also, reduces environmental burdens (Zaman and Swapan, 2016). Nevertheless, landfill remains the end-of-life option that is pursued for the majority of the construction materials utilised in buildings (Kookos et al., 2019).

The European Commission has, indeed, adopted a CE-Package, to propose a $65 \%$ target for municipal waste recycling and to reduce its landfill to a maximum of $10 \%$ by 2030 . Unfortunately, it currently stands that only $35 \%$ of the non-compostable fraction of municipal waste is recycled and almost $30 \%$ is still committed to landfill (Arrigoni et al., 2018). Such an aspect further emphasises upon the need for sustainability-oriented strategies, to: minimise, through a set of measures and actions, environmental and socio-economic burdens associated with the management of solid wastes (from collection to treatment); and to favour their recovery and recycling (Põldnurk, 2015).

Within this context, it is no surprise for this guest editorial group that the valorisation of wastes through sustainable management scenarios is by now a global matter that is increasingly raising attention and interest of researchers, producers, and decision and policy makers. Waste valorisation has multiple key-roles for the sustainability of a huge number of sectors (Valenti et al., 2017), like buildings and civil works, and can contribute to sustainable development pathways at the urban and rural context.

Unfortunately, major competitions are occurring nowadays upon by-product and waste streams, actually because they are increasingly being utilised for production of material commodities that find application in a wide range of sectors: buildings are one of those. This is the instance case of straw that is by now widely accepted and treated as a cereal cultivation by-product, and is increasingly being utilised in buildings as enveloping material with insulation function (Ingrao et al., 2017) or also as biofuel in direct combustion applications for production of building material commodities (Ingrao et al., 2019).

Hence, investigation and research is recommended for innovation and improvement and, for that, studies have been developed - and several others of those are expected in the future - to address 
technological, logistics, environmental, socio-economy, market, governance, legislation and policy aspects for the sustainability of waste management systems; and support the development of sustainabilityoriented strategies, guidelines, legislations and policies.

In this context, this Virtual Special Issue1 (VSI) was accommodated in this journal to motivate prominent researchers to explore the relevance of addressing - and possibly interconnecting - those aspects for the assessment, improvement, encouragement and promotion of sustainability of by-product and waste management systems as involved in the production of building material commodities.

\section{Scope of this virtual special issue}

This VSI was developed based upon the concern that sustainable buildings, and more generally built environments can feed the transition to equitable, sustainable, post fossil-carbon societies, as of Ingrao et al. (2016) and Ingrao et al. (2018c). A transition towards societies and economies where by-product and waste streams are managed in more responsible and sustainable manners and so are processed into green building materials (Ingrao et al., 2017). However, the transition must be properly envisioned, designed, tested, and implemented to ensure sustainable production, distribution and consumption of sustainable building material commodities (Ingrao et al., 2018c). Furthermore, if properly made, it will help to catalyse improvements in technological quality, socio-economic equity and environmental sustainability of buildings in holistically integrated ways (Ingrao et al., 2018c).

In this context, the central purpose of this VSI was to highlight the importance of the academic research in documenting ways for theoretical concepts, tools, technologies, practices and policies to enable, assess and stimulate sustainability of building materials and, more generally, of buildings.

In particular, the VSI was conceived to collect relevant studies investigating sustainability-related issues in the production of building material commodities using by-product and waste streams, and so to serve as a solid platform for enhancement of knowledge on emerging methods, practical implementations, state-for-the-arts analyses, findings and lessons learned in this area of research.

Finally, this editorial arises with the aim of reviewing and building upon the papers that have been included in this VSI, to highlight main objectives and findings and so their contributions to the specialised literature.

\section{Overview of the papers included in this virtual special issue}

This VSI attracted huge interest and attention from the scientific community worldwide with the submission of nearly 30 papers, which exceeded expectations of the guest editorial team members. Following the responsibility of the 'Resources, Conservation, and Recycling' journal all articles were subjected to in-depth, constructive reviews, with the objective of improving their quality and scientific relevance. A total of 10 papers were accepted for publication, so representing $36 \%$ of the overall submissions collected: they were submitted by 10 (corresponding) authors from several countries worldwide, but were the result of the joint work and commitment made by a total of 46 authors from numerous parts of the world (Fig. 1). This shows that research development is often taken as the occasion to strengthen ongoing collaborations at the international level and create new ones.

In their papers, the authors dealt with several materials, which were classified in this review study based upon their enveloping, filling, and/ or insulating function: those papers were reviewed in Section 3.1.

Finally, a few other papers addressed general concerns, like those related to: decarbonisation of the building sector in a CE context (Nußholz et al., 2019); value creation in circular business models (Ünal et al., 2019); and Construction and Demolition (C\&D) waste management (Gálvez-Martos et al., 2019). In this regard, it should be 
underscored that a significant share of municipal waste is constituted by C\&D debris (Arrigoni et al., 2018). Every year, the construction sector produces in Europe 820 million tonnes of C\&D waste, so contributing nearly $46 \%$ of the overall-generated amount of waste (GálvezMartos et al., 2019). Concrete, ceramics and masonries represent, on an average, up to $85 \%$ of a standard C\&D waste, and so can be considered as the largest components (Arrigoni et al., 2018; Gálvez-Martos et al., 2019). However, there can be found large amounts of wood and plasterboard, thereby making C\&D waste someway heterogeneous with differences in composition, depending upon the origin from which that waste was generated (Gálvez-Martos et al., 2019). C\&D waste is characterised by high levels of volume and weight, and by the highest inert fraction compared to other waste streams. Furthermore, each tonne of $\mathrm{C}$ \&D waste is not exempt from generating environmental impacts but these are, anyway, lower than other waste streams. This changes drastically if one looks at the high amount produced overall in Europe, which is the reason why C\&D waste management has become a global concern (Gálvez-Martos et al., 2019) and an important issue to be addressed urgently, from an environmental and socio-economic point of view. In this regard, it is essential to clearly define and share best practice techniques to develop new policy and strategy frameworks that can positively contribute sustainable development in the construction sector (Gálvez-Martos et al., 2019). This field of research was investigated by Gálvez-Martos et al. (2019): in their paper, the authors synthesised indeed main principles standing behind the definition of best practices for the management of C\&D waste. Great heterogeneity was found in the study amongst European Member States (EMSs), with special regard to: treatment of waste and development of markets for secondary materials. In addition to this, the authors interestingly highlighted that, though technologies and potentials for high performing C\&D waste management systems are already available in the market, the construction sector shows behaviours that are heavily based upon traditional standards as fully economically driven. Finally, the high variety of actors involved in the C\&D waste value chain creates a complex mesh of responsibilities, with very different decision-making chains across EMSs (Gálvez-Martos et al., 2019).

Huge geographical variability was documented by Arrigoni et al. (2018) in the rate C\&D waste is re-used or recycled, with values from $5 \%$ in China to $95 \%$ in the Netherlands, with $30-60 \%$ ranges in many other European countries.

C\&D waste can be either re-used in its original form or, most commonly, can be re-processed into coarse or fine aggregates (Arrigoni et al., 2018), so generating secondary building materials for a wide range of applications. Several research studies highlighted the increasing need for sustainable new construction to increase the percentage of materials re-utilised or recycled at the end of a building life cycle (Leising et al., 2018; Ünal et al., 2019). Such - and other related practices enable reduction of embodied carbon emissions, so resulting to be vital for decarbonisation of the building sector (Nußholz et al., 2019). This research area was studied by Nußholz et al. (2019) who understood and brought to readers' attention: the relevance of strategies for utilising secondary materials to decarbonise the building sector; and the interplay of policy and business model innovation to advance those strategies. The authors highlighted that carbon saving potentials are strictly dependent upon which of the harmful processes in primary material production are replaced through the usage of secondary materials and the indirect consequences at the industry level (Nußholz et al., 2019). In this regard, Nußholz et al. (2019) recommended processes and markets to be duly accounted for at both levels of product and industry to ensure actual carbon savings, especially in the case of strategy selection to give support to policy initiatives. Finally, the authors found critical business model innovation for implementation of secondary material usage to revolve around development of recovery technologies and capabilities, and partner networks for access to secondary raw materials (Nußholz et al., 2019). All partners (i.e. suppliers of raw materials, manufacturers, retailers, and designers) involved in establishing buildings meeting CE principles should consider implementing practices that reshape the design of their supply chain and build their own circular business model (Ünal et al., 2019). This area of research was explored by Ünal et al. (2019), who documented that recycling natural and local waste in buildings is essential for circular business models, by considering the impact on stakeholders. Moreover, Ünal et al. (2019) found that, in the building sector, CE requires business model adaptability in terms of value creation process. This can be achieved by creating circular business models to be based upon internal and external contextual conditions, and by regenerating natural waste through aligned managerial practices, sociocultural and socioeconomic settings and sustainable behaviours amongst supply chain actors (Ünal et al., 2019). Finally, in line with Gálvez-Martos et al. (2019); Ünal et al. (2019) reported that the building sector is by nature characterised by a large network of highly-interconnected and co-working suppliers, collaborators and employees; not to mention the long life cycles of products and the high economic rents. In the light of this, Ünal et al. (2019) interestingly concluded that, in buildings as in any other productive sector, a circular business model enables co-creation of the shared value and so provides robust opportunities for regional regeneration at the environmental and socio-economic level.

\subsection{Review of papers assessing specific categories of building material commodities}

This section was dedicated to reviewing studies where specific categories of building products have been tested from a technical, environmental and/or socio-economic perspective.

Several by-product and/or waste streams can be utilised for production of building material commodities in a CE context: one of those is represented by demolished concrete. Once generated, such a waste stream is sorted and re-processed into coarse Recycled Concrete Aggregates (RCAs) for application as base or sub-base in road works, as natural aggregate substitutes in the manufacturing of fresh concrete or as backfilling material in quarries and foundations (Arrigoni et al., 2018). However, there are also innovative viable paths for demolished concrete re-utilisation, like that of ramming it into layers to form loadbearing walls for Stabilised Rammed Earth ${ }^{1}$ (SRE) applications (Hall and Swaney, 2005; Arrigoni et al., 2018). Whilst the field of RCA production and application has been extensively investigated, a very few studies have been carried out over the course of the last years to explore RCA utilisation in SRE applications (Arrigoni et al., 2018).

In this context, Arrigoni et al. (2018) built upon those studies and, then, evaluated SRE samples with different RCA contents, by focalising attention upon environmental sustainability issues, as well as other issues related to material mechanical behaviour, durability, and hygroscope and microstructure. Different mixtures were evaluated by the authors and provided: RCAs, excavated in-situ soil, and/or crushed limestone as substrates; and cement and/or fly ash as additives. Different weight-percentages of application were considered depending upon the mixture: $0 \%-100 \%$ for the substrates; and $5 \%-10 \%$ for the additives (Arrigoni et al., 2018). The study, together with that from Arrigoni et al. (2017), through application of attributional and consequential LCA, highlighted that using RCA in replacement of quarried products generates several environmental benefits. These were attributed by the authors mainly to: avoided occupation of mineral extraction sites; avoided exploitation of resources and energy for raw material production, with subsequent avoided emissions of Greenhouse Gases (GHGs); and avoided landfill scenarios. However, since both studies

\footnotetext{
${ }^{1}$ Rammed earth (RE) is an ancient construction procedure where walls are built by compacting an earthen mixture between formwork. SRE is a modern form of rammed earth in which a (usually cementitious) binder is added to the earth mix for improvement of the material's mechanical resistance (Arrigoni et al., 2018).
} 
regard assessment of mixture-based samples, the authors found sustainability results to be highly dependent upon the types and amounts of the other materials utilised to form the mixture. With regard to this point, the authors documented that including fly ash in the mixture and reducing the cement content to $5 \%$ led to a net reduction of the life cycle GHG-emissions of up to $15 \mathrm{~kg} \mathrm{CO}$ eq. $/ \mathrm{m}^{2}$ without compromising mechanical resistance or durability (Arrigoni et al., 2018). However, it should be underscored that negative influences could be exhibited by the surrounding conditions on the environmental sustainability of RCAcontaining products, as is for the majority of the system-level LCAs. For instance, as highlighted by Arrigoni et al. (2018), if RCAs were transported for long distances prior to usage in the building construction site, it may be more sustainable for some impact categories, like nonrenewable energy and global warming, to use natural aggregates.

The mixture made only from excavated in-situ soil could be considered, indeed, as the optimal rammed earth solution in terms of sustainability and moisture buffering ability. However, when that soil is not available for earthen structures or greater resistances, rammedRCAs may represent a valid alternative option (Arrigoni et al., 2018).

Another waste stream is represented by the sulphur-free and low molecular lignin polymers being yielded from the organosolv process ${ }^{2}$. According to Hildebrandt et al. (2019), the obtained lignin is a very valuable component for replacing phenolic compounds within phenolic resin systems. However, its feasibility and sustainability of application for manufacturing of products and components for buildings is still under evaluation. This is mainly because there is a wide range of degrees for substitution of fossil-based resins and mineral fibres (from low substitution to high substitution) and their impact on mechanical properties and environmental performance (Hildebrandt et al., 2019). Hildebrandt et al. (2019) contributed this research field, by technoenvironmentally assessing laminates made out of beech wood fibres and a thermoset binder system based on lignin-based phenolic resin. Interestingly, the authors evaluated different production scenarios that were developed by operating changes in the shares of the resin matrix (RM) and the lignin content within the RM. Additionally, the share of fresh wood was varied against an alternative share of saw-mill by-products from fresh wood assortments, with $20 \%$ and $100 \%$ substitutions (Hildebrandt et al., 2019). This study was based upon LCA application to evaluate the environmental impacts and potential benefits that can be obtained by varying shares of resins, of fibre content and of lignin, within the resin matrix. Through their study, the authors documented that the optimised usage of a beech wood feedstock for substitution of fossil-based phenolic resin and the high wood-based fibre content offer potentials for enhancing the environmental performance that are far higher than those attainable by extending the coupled use of saw mill by-products. Finally, based upon findings from the study it can be concluded that the beech fibre laminates with $20 \%$ resin matrix, $20 \%$ of lignin content, and $80 \%$ fibre content by weight in the final board exhibits the most optimal mechanic properties and shows the lowest negative environmental impacts, compared to the other scenarios considered. Sustainability of those laminates were documented by Hildebrandt et al. (2019) to be improvable if that $80 \%$ fibre content is contributed partially $(20 \%)$ or - even better - totally (100\%) by sawmill by-products.

The development of composites using petroleum-derived polymer matrices reinforced with natural fibres has attracted significant attention in civil engineering applications (Kookos et al., 2019). However, production of plastics from non-renewable resources causes a set of environmental hotspots mainly related to resource depletion and GHG emission (Ingrao et al., 2015). In particular, $\mathrm{CO}_{2}$ emission from fossil fuel combustion represents a major contributor to global warming (GW)

\footnotetext{
${ }^{2}$ This is a thermo-chemical process applied in lignocellulosic bio-refineries to fractionate wood resources into their components cellulose, lignin and hemiccellulose (Hildebrandt et al., 2019).
}

and could have potentially devastating social, economic and environmental consequences in the future, if not addressed (Colwill et al., 2012). This is such a global concern that emphasises upon the need for alternatives to petroleum mineral-based products and processes (Ingrao et al., 2015). In fact, the continuous search for more environmentally sustainable material options has been receiving the attention of a broad research community at the global level (Paiva et al., 2012). In this context, production of biodegradable polymers from renewable resources should be adopted to tackle the environmental problems caused by petroleum-derived plastics as proposed by many literature-cited studies (Kookos et al., 2019). Poly(3-hydroxybutyrate) (PHB) is one of those polymers and, amongst several other uses like barrier packaging material in biomedicine and food industry (Siracusa et al., 2017), is finding increasing applications in the production of fibre reinforced biocomposites (Khoshnava et al., 2017). In this context, the aim of Kookos's et al. (2019) study was that of performing a full LCA of production of PHB from soybean cultivation, also in comparison with production of polymers from non-renewable petrochemical resources. The study was characterised by detailed inventory and impact assessments of PHB production in order to compare the obtained results with literature-cited publications (Kookos et al., 2019). From results, PHB production is advantageous compared to its petrochemical counterpart. In addition to this, GHG emissions, non-renewable energy use, as well as acidification and eutrophication potentials associated with PHB production were found to be strongly dependent upon the specific renewable raw material used and the allocation methodology adopted (Kookos et al., 2019). So, it is understandable why differences in results were recorded by the authors with previously-published literature studies. Finally, Kookos et al. (2019) suggested investigation of alternative raw materials especially agricultural residues and side streams from the food industry. Doing so would make it possible to offer several advantages over dedicated crops when combined with the development of integrated biorefineries (Kookos et al., 2019).

Yet another residual stream that is worth mentioning is that of the bauxite outlet from the first stage of aluminium production (Joyce et al., 2018). Its treatment has long been a concern of the alumina industry (Evans, 2016; Joyce et al., 2018), so much so that more sustainable disposal scenarios, other than the classic landfilling, are currently under development (Joyce et al., 2018). One valid way for recovery of the Bauxite Residue (BR) would be that of recycling it into building materials, so enabling high-volume valorisation of this waste. This would also meet the increasing demand from the construction industry for building materials demonstrating high environmental performance (Joyce et al., 2018). In their study, Joyce et al. (2018) dealt with such a research theme, with the aim of identifying: potential hotspots of environmental impact in the production of paving blocks from novel high BR-content inorganic polymers; and opportunities for impact reduction prior to the final development and subsequent approval of the technology. For the purpose of the study development, the authors applied an anticipatory Life Cycle Assessment (LCA) to the early stages of the design and development of the technology, so using data from lab-scale experiments. From the study, it was highlighted that the energy consumed in the BR firing process is the most significant hotspot of impact, and represents a high priority target for improvement (Joyce et al., 2018). Though utilisation of this energy is thermodynamically unavoidable, the authors suggested options for reduction of the resulting environmental impact. One of those options, for immediate future application, could be that of firing with 'clear burning fuels' like natural gas, so enabling impact decrease for all impact categories considered in the study, but ozone layer depletion (Joyce et al., 2018). Such a result should be attributed to emissions of the ozone depleting substances (i.e. Halon 1301 and Halon 1211) which are required for usage as fire suppressants in the production and transmission of natural gas (Joyce et al., 2018). In the medium-long term, new heating methods, like those providing microwave, was suggested by Joyce et al. (2018) to offer a more sustainable outlook. This agrees with 
Falciglia et al. (2018), who documented that microwave heating is one environmentally valid option for application for remediation of hydrocarbon-contaminated marine sediments, compared to other physical-chemical technologies like the electro-kinetic.

The manufacturing of blocks for buildings was also investigated by Kanchanapiya et al. (2018), but this time those were made out of Lightweight Concrete (LWC): in their study, the authors carried out research to determine the most suitable blends for production of LWCs mixed with Polyisocyanurate (PIR) foam waste (PIRW). The driving goal was not only to meet industrial standards but also to achieve economic feasible production practices from the viewpoint of the PIR foam manufacturers: the authors achieved the proposed goal. As a matter of fact, their study documented a thermal conductivity value for the LWC-PIRW blocks under testing $\left(0.36 \mathrm{~W} / \mathrm{m}{ }^{\circ} \mathrm{K}\right)$ to be fully in line with that of other typical foamed concretes. In addition to this, results from the study highlighted that LWC-PIRW block production to be economically feasible with a net present value equal to 34,570 USD and a $21.5 \%$ internal rate of return. So, in agreement with Kanchanapiya et al. (2018), it can be asserted that, thanks to their insulating properties, production of blocks made out of suitable blends of LWC and PIRW can favour efficient management of waste streams and saving of energy from indoor conditioning during building operation.

Several other insulating materials and products are currently available in the market for applications in buildings: the majority of them derive from mineral wool and plastics, and only a small part is natural (Barreca et al., 2019). A set of advantages warrant utilisation of natural materials in buildings, including the lower energy for indoor temperature control (Barreca et al., 2019), and the capture of carbon dioxide $\left(\mathrm{CO}_{2}\right)$ during plantation growth (Zampori et al., 2013; Barreca et al., 2019). In the past, agricultural or forestry residues were widely utilised in rural farms as building components, or as complementary materials, mainly with cladding and insulating functions (Väisänen et al., 2016; Barreca et al., 2019). This field was contributed by the research that Barreca et al. (2019) conducted with the aim of energy and environmentally testing building elements made out of two typical natural materials of the Mediterranean area, namely giant reed (Arundo donax L.), and agglomerated cork. In particular, the authors analysed a cavity wall panel made by a wood skeleton on which two double crossed layers of giant reed stems were fixed, and a multilayer agglomerated cork wall with a double cavity composition (Barreca et al., 2019). The wall composition designed was characterised in terms of heat transmittance, showing a value largely lower than that of a standard brick-based composition. In addition to this, energy consumption for indoor heating and cooling was estimated through a dynamic thermal analysis in the context of a hypothetic single-floor Mediterranean house. As the consequence of the better insulation performances, buildings where those two natural material based composition were utilised recorded the lowest energy demands. Finally, with regard to the assessment of environmental issues, the authors focussed attention upon the $\mathrm{CO}_{2}$-emission saving (with respect to the standard brick wall) during heating and cooling, which was estimated to be equal to $75 \%$ in the case of agglomerate cork and $26 \%$ when giant reed is utilised (Barreca et al., 2019).

In another study, Ingrao et al. (2019) focussed attention upon utilisation of straw as a by-product from Durum Wheat (DW) cultivation in Sicily. Based upon Chinnici et al. (2015), local management practices provide $90 \%$ of the straw produced in Sicily to be utilised in farmlands as animal feed, or is burned just after the cereal harvest to improve the organic matter content of the soils. The remaining $10 \%$ is destined to other applications, including a series of innovative ones like renewable feedstock in anaerobic digestion plants or building material with enveloping and insulating functions (Ingrao et al., 2019). Additionally, straw can find feasible applications as fuel in direct combustion processes for generation of energy usable in a wide range of sectors (Ingrao et al., 2019). However, Giuntoli et al. (2013) highlighted a gap in the literature with regard to environmental sustainability of straw-fired installations: Ingrao et al. (2019) investigated such a research area and gave an attempt in contributing filling that existing gap. In their study, the authors addressed life-cycle environmental issues related to a strawfired installation in an industrial system for production of Expanded Clay Granulates (ECG). In particular, within that system, straw is subjected to direct combustion in a rotary kiln to produce heat, as required for cooking and expansion of input fresh-clay granulates (Ingrao et al., 2019). The study was conducted in collaboration with a local ECG producing firm, which changed the type of solid fuel to be combusted in the kilning step for cooking and expansion of input fresh clay (Ingrao et al., 2019). As clarified by Ingrao et al. (2019), the research was aimed at validating, from an environmental perspective, the firm choice by carrying out a comparative LCA of the two plant configurations, based upon utilisation of different fuels: hard coal (ante-operam); and DW straw (post-operam). The proposed goal was achieved, as the study confirmed renewable biomasses, like straw, to be alternative fuels to decrease the environmental impacts associated with building material production systems. In detail, from the study it was found that DW straw production is more impacting than hard coal, because greater amounts were used per cubic metre of ECG. However, on equal amount used, hard coal generates higher environmental burdens associated with its production, compared to those coming from straw production. According to Ingrao et al. (2019) the environmental damage in the ante-operam plant was documented to be higher than in the post-operam one, mainly because of the presence of hard coal generating huge emissions of $\mathrm{CO}_{2}$, thus strengthening the imperative need to accelerate the transition from fossil to renewable energy sources. Finally, the study sustains the belief that replacing fossil fuels (i.e. coal) with agricultural residues (i.e. straw) may represent an environmentally friendly method for the management of those residues and a suitable way for conservation of fossil fuels and natural resources (Ingrao et al., 2019).

Finally, all papers included in the VSI and reviewed in this introductory article were classified in Table 1, based upon: the publication year; the first-author names (in alphabetic order); the category of building product and related function within the building structure; the (waste) material utilised; and the assessment conducted.

\section{Conclusions}

This VSI achieved the proposed goal, namely that of collecting selected relevant studies with the aim of addressing sustainability of byproduct and waste management systems, to produce building material commodities. It allowed documenting that the usage of by-product and waste streams enables environmental and economic sustainability of building material commodities making them valid alternatives to the virgin counterparts, whether their quality and functionality is not compromised.

All articles accepted for publication and included in this VSI were characterised by a clear discussion about: the peculiarities of the researches they were reporting upon and the ways they contributed the subject literature and knowledge; and the practical, environmental, and economic implications of those researches.

In addition to this, the majority of them provided a material design/ formulation, characterisation and testing phase prior to that for assessment of environmental, and/or socio-economic issues by means of tools like LCA and cost analysis. In this way, through this VSI, it was proven once again that such methodologies can exhibit multiple key roles for assessment and improvement of economic-environmental issues already in the design phase.

Moreover, the significant response to this VSI was particularly encouraging, because it has proven that academic communities continue to scale up research on topics related to usage of by-product and waste streams for production of building material commodities. More importantly than that, researches were translated into applications outside of academia. According to this VSI guest editors, this will make it possible not only to provide a platform to exchange knowledge and best 
practices, but also to ask new questions for future academic research.

Finally, scanning through the working teams of the papers it was observed that several of them are composed by authors from worldwide countries and/or from different affiliations in the same country, so highlighting the importance of joint work for research development. In addition, the guest editors believe that this VSI has been a valuable occasion to strengthen ongoing collaborations at the international level and create new ones.

\section{Acknowledgements}

Dr. Carlo Ingrao, as the Managing Guest Editor of this VSI, would like to thank all the guest editorial board members because, without their supportive commitment and work, this VSI would have never been possible. In addition to this, the whole guest editorial board would like to thank all the authors for contributing as high-quality manuscripts to this VSI as they have. Their relevant work will make it possible for this VSI to play the role of a valid tool to spread knowledge on ways waste management systems influence sustainability of buildings.

Finally, special thanks are conveyed to Prof. Ming Xu (Esteemed Editor-in-Chief of the Journal) for having supported, guided and supervised the development of this VSI project since the very beginning of its conception.

\section{References}

Arbolino, R., Carlucci, F., Cirà, A., Ioppolo, G., Yigitcanlar, T., 2017. Efficiency of the EU regulation on greenhouse gas emissions in Italy: the hierarchical cluster analysis approach. Ecol. Indic. 81, 115-123.

Arrigoni, A., Beckett, C., Ciancio, D., Dotelli, G., 2017. Life cycle analysis of environmental impact vs. Durability of stabilised rammed earth. Constr. Build. Mater. 142, $128-136$.

Arrigoni, A., Beckett, C.T.S., Ciancio, D., Pelosato, R., Dotelli, G., Grillet, A.-C., 2018. Rammed Earth incorporating Recycled Concrete Aggregate: a sustainable, resistant and breathable construction solution. Resour. Conserv. Recycl. 137, 11-20.

Asdrubali, F., Baldassari, C., Fthenakis, V., 2013. Life cycle analysis in the construction sector: guiding the optimization of conventional Italian buildings. Energy Build. 64, 73-89.

Babbitt, C.W., Gaustad, G., Fisher, A., Chen, W.-Q., Liu, G., 2018. Closing the loop on circular economy research: from theory to practice and back again. Resour. Conserv. Recycl. 135, 1-2.

Barreca, F., Martinez Gabarron, A., Flores Yepes, J.A., Pastor Pérez, J.J., 2019. Innovative use of giant reed and cork residues for panels of buildings in Mediterranean area. Resour. Conserv. Recycl. 140, 259-266.

Berardi, U., 2017. A cross-country comparison of the building energy consumptions and their trends. Resour. Conserv. Recycl. 123, 230-241.

Chinnici, G., D’Amico, M., Rizzo, M., Pecorino, B., 2015. Analysis of biomass availability for energy use in Sicily. Renew. Sustain. Energy Rev. 52, 1025-1030.

Colwill, J.A., Wright, E.I., Rahimifard, S., 2012. A holistic approach to design support for bio-polymer based packaging. J. Polym. Environ. 20, 1112-1123.

Dixit, M.K., Fernández-Solís, J.L., Lavy, S., Culp, C.H., 2012. Need for an embodied energy measurement protocol for buildings: a review paper. Renew. Sustain. Energy Rev. 16, 3730-3743.

Evans, K., 2016. The history, challenges, and New developments in the management and use of bauxite residue. J. Sustain. Metall. 2, 316-331.

Falciglia, P.P., Ingrao, C., De Guidi, G., Catalfo, A., Finocchiaro, G., Farina, M., Liali, M., Lorenzano, G., Valastro, G., Vagliasindi, F.G.A., 2018. Environmental Life Cycle Assessment of marine sediment decontamination by citric acid enhanced-microwave heating. Sci. Total Environ. 619-620, 72-82.

Gálvez-Martos, J.-L., Styles, D., Schoenberger, H., Zeschmar-Lahl, B., 2019. Construction and demolition waste best management practice in Europe. Resour. Conserv. Recycl. 136, 166-178.

Giuntoli, J., Boulamanti, A.K., Corrado, S., Motegh, M., Agostini, A., Baxter, D., 2013. Environmental impacts of future bioenergy pathways: the case of electricity from wheat straw bales and pellets. Gcb Bioenergy 5, 497-512.

Goulart Coelho, L.M., Lange, L.C., 2016. Applying life cycle assessment to support environmentally to support environmentally sustainable waste management strategies in Brazil. Resour. Conserv. Recycl. 128, 438-450.

Govindan, K., 2015. Green sourcing: taking steps to achieve sustainability management and conservation of resources. Resour. Conserv. Recycl. 104, 329-333.

Hall, M., Swaney, B., 2005. Stabilised rammed earth (SRE) wall construction - now available in the UK. Build. Eng. 80 (9), 12-15.

Hildebrandt, J., Budzinski, M., Nitzsche, R., Weber, A., Krombholz, A., Thrän, D., Bezama, A., 2019. Assessing the technical and environmental performance of wood-based fiber laminates with lignin based phenolic resin systems. Resour. Conserv. Recycl. 141, 455-464.

Ingrao, C., Lo Giudice, A., Tricase, C., Rana, R., Mbohwa, C., Siracusa, V., 2014. RecycledPET fibre based panels for building thermal insulation: environmental impact and improvement potential assessment for a greener production. Sci. Total Environ. 493, 914-929.

Ingrao, C., Tricase, C., Cholewa-Wójcik, A., Kawecka, A., Rana, R., Siracusa, V., 2015. Polylactic acid trays for fresh-food packaging: a Carbon Footprint assessment. Sci. Total Environ. 537, 385-398.

Ingrao, C., Bacenetti, J., Bezama, A., Blok, V., Geldermann, J., Goglio, P., Koukios, E.G., Lindner, M., Nemecek, T., Siracusa, V., Zabaniotou, A., Huisingh, D., 2016. Agricultural and forest biomass for food, materials and energy: Bio-economy as the cornerstone to cleaner production and more sustainable consumption patterns for accelerating the transition towards equitable, sustainable, post fossil-carbon societies. J. Clean. Prod. 117, 4-6.

Ingrao, C., Arcidiacono, C., Bezama, A., Ioppolo, G., Winans, K., Koutinas, A., GallegoSchmid, A., 2017. Sustainability issues of by-product and waste management systems to produce building material commodities. Resour. Conserv. Recycl. 126, 4-5.

Ingrao, C., Messineo, A., Beltramo, R., Yigitcanlar, T., Ioppolo, G., 2018a. How can life cycle thinking support sustainability of buildings? Investigating life cycle assessment applications for energy efficiency and environmental performance. J. Clean. Prod. 201, 556-569.

Ingrao, C., Faccilongo, N., Di Gioia, L., Messineo, A., 2018b. Food waste recovery into energy in a circular economy perspective: a comprehensive review of aspects related to plant operation and environmental assessment. J. Clean. Prod. 184, 869-892.

Ingrao, C., Bacenetti, J., Bezama, A., Blok, V., Goglio, P., Koukios, E.G., Lindner, M., Nemecek, T., Siracusa, V., Zabaniotou, A., Huisingh, D., 2018c. The potential roles of bio-economy in the transition to equitable, sustainable, post fossil-carbon societies: findings from this virtual special issue. J. Clean. Prod. 204, 471-488.

Ingrao, C., Selvaggi, R., Valenti, F., Matarazzo, A., Pecorino, B., Arcidiacono, C., 2019. Life cycle assessment of expanded clay granulate production using different fuels. Resour. Conserv. Recycl. 141, 398-409.

Intini, F., Kühtz, S., 2011. Recycling in buildings: an LCA case study of a thermal insulation panel made of polyester fiber, recycled from post-consumer PET bottles. Int. J. Life Cycle Assess. 16, 306-315.

Joyce, P.J., Hertel, T., Goronovski, A., Tkaczyk, A.H., Pontikes, Y., Björklund, A., 2018. Identifying hotspots of environmental impact in the development of novel inorganic polymer paving blocks from bauxite residue. Resour. Conserv. Recycl. 138, 87-98.

Kanchanapiya, P., Methacanon, P., Tantisattayakul, T., 2018. Techno-economic analysis of light weight concrete block development from polyisocyanurate foam waste. Resour. Conserv. Recycl. 138, 313-325.

Khoshnava, S.M., Rostami, R., Ismail, M., Rahmat, A.R., Ogunbode, B.E., 2017. Woven hybrid biocomposite: mechanical properties of woven kenaf bast fibre/oil palm empty fruit bunches hybrid reinforced polyhydroxybutyrate biocomposite as nonstructural building materials. Constr. Build. Mater. 154, 155-166.

Kirchherr, J., Reike, D., Hekkert, M., 2017. Conceptualizing the circular economy: an analysis of 114 definitions. Resour. Conserv. Recycl. 127, 221-232.

Kookos, I.K., Koutinas, A., Vlysidis, A., 2019. Life cycle assessment of bioprocessing schemes for poly(3-hydroxybutyrate) production using soybean oil and sucrose as carbon sources. Resour. Conserv. Recycl. 141, 317-328.

Korhonen, J., Honkasalo, A., Seppälä, J., 2018. Circular economy: the concept and its limitations. Ecol. Econ. 143, 37-46.

La Rosa, A.D., Recca, A., Gagliano, A., Summerscales, J., Latteri, A., Cozzo, G., Cicala, G., 2014. Environmental impacts and thermal innovation performance of innovative composite solutions for building applications. Constr. Build. Mater. 55, 406-414.

Leising, E., Quist, J., Bocken, N., 2018. Circular Economy in the building sector: three cases and a collaboration tool. J. Clean. Prod. 176, 976-989.

Moreau, V., Sahakian, M., Van Griethuysen, P., Vuille, F., 2017. Coming full circle: why social and institutional dimensions matter for the circular economy. J. Ind. Ecol. 21 (3), 497-506.

Nußholz, J.L.K., Nygaard Rasmussen, F., Milios, L., 2019. Circular building materials: carbon saving potential and the role of business model innovation and public policy. Resour. Conserv. Recycl. 141, 308-316.

Paiva, A., Pereira, S., Sá, A., Cruz, D., Varum, H., Pinto, J., 2012. A contribution to the thermal insulation performance characterization of corn cob particleboards. Energy Build. 45, 274-279.

Põldnurk, J., 2015. Optimisation of the economic, environmental and administrative efficiency of the municipal waste management model in rural areas. Resour. Conserv. Recycl. 97, 55-65.

Ramesh, T., Prakash, R., Shukla, K.K., 2010. Life cycle energy analysis of buildings: an overview. Energy and Building 42 (10), 1592-1600.

Rincon, L., Coma, J., Perez, G., Castell, A., Boer, D., Cabeza, L.F., 2014. Environmental performance of recycled rubber as drainage layer in extensive green roofs. A comparative Life cycle Assessment. Build. Environ. 74, 22-30.

Saavendra, Y.M.B., Iritani, D.R., Pavan, L.R., Ometto, A.R., 2018. Theoretical contribution of industrial ecology to circular economy. J. Clean. Prod. 170, 1514-1522.

Siracusa, V., Ingrao, C., Karpova, S.G., Olkhov, A.A., Iordanskii, A.L., 2017. Gas transport and characterization of poly(3 hydroxybutyrate) films. Eur. Polym. J. 91, 149-161.

Ünal, E., Urbinati, A., Chiaroni, D., Manzini, R., 2019. Value creation in circular business models: The case of a US small medium enterprise in the building sector. Resour. Conserv. Recycl. https://doi.org/10.1016/j.resconrec.2018.12.034.

Väisänen, T., Haapala, A., Lappalainen, R., Tomppo, L., 2016. Utilization of agricultural and forest industry waste and residues in natural fiber-polymer composites: a review. Waste Manage. 54, 62-73.

Valenti, F., Porto, S.M.C., Chinnici, G., Selvaggi, R., Cascone, G., Arcidiacono, C., Pecorino, B., 2017. Use of citrus pulp for biogas production: a GIS analysis of citrus growing areas and processing industries in South Italy. Land Use Policy 66, 151-161.

Venkata Mohan, S., Annie Modestra, J., Amulya, K., Butti, S.K., Velvizhi, G., 2016. A circular bioeconomy with biobased products from $\mathrm{CO}_{2}$ sequestration. Trends Biotechnol. 34 (6), 506-519. 
Zaman, A.U., Swapan, M.S.H., 2016. Performance evaluation and benchmarking of global waste management systems. Resour. Conserv. Recycl. 114, 32-41.

Zampori, L., Dotelli, G., Vernelli, V., 2013. Life cycle assessment of hemp cultivation and use of hemp-based thermal insulator materials in buildings. Environ. Sci. Technol. 47, 7413-7420.

Carlo Ingrao

Faculty of Engineering and Architecture, Kore University of Enna, Enna,

Italy

Claudia Arcidiacono*

Department of Agriculture, Food and Environment (Di3A), University of Catania, Catania, Italy E-mail address: claudia.arcidiacono@unict.it.

Alberto Bezama

Helmholtz Centre for Environmental Research - UFZ, Leipzig, Germany
Giuseppe Ioppolo Department of Economics, University of Messina, Messina, Italy

Kiara Winans

Department of Civil \& Environmental Engineering, Agricultural Sustainability Institute, University of California, United States

Apostolis Koutinas

Department of Food Science and Human Nutrition, Agricultural University of Athens, Greece

Alejandro Gallego-Schmid School of Chemical Engineering and Analytical Science, The University of Manchester, Manchester, United Kingdom

* Corresponding author. 